\title{
ЗНАЧЕНИЕ ОНКОЛОГИЧЕСКОЙ НАСТОРОЖЕННОСТИ В ПРАКТИЧЕСКОЙ МЕДИЦИНЕ
}

\section{THE IMPORTANCE OF ONCOLOGICAL VERIFICATION IN PRACTICAL MEDICINE}

Kh. Bisemalieva

A. Stupin

Summary. The article examines the issues of oncological alertness, its necessity in the practice of a doctor, as well as the awareness of the population about the prevention of oncological diseases. The research materials are based on questionnaires of various age groups. Purpose: to assess the importance of cancer alertness in medicine. The result of the study: establishing the need for oncological alertness.

Keywords: malignant and benign tumors; oncological alertness; survey; pre-cancers; malignancy.

\author{
Бисемалиева Хадиша Фархатовна \\ ФГБОУ ВО «Астраханский ГМУ» Минздрава России \\ fbisemaliev@mail.ru \\ Ступин Андрей Олегович \\ ФГБОУ ВО «Астраханский ГМУ» Минздрава России \\ euaristus@mail.ru
}

Аннотация. В статье рассматриваются вопросы онкологической настороженности, ее необходимости в практике врача, а также осведомленности населения по поводу профилактики онкологических заболеваний. Материалы исследования опираются на анкетирование различных возрастных групп. Цель: оценка важности онкологической настороженности в медицине. Результат исследования: установление необходимости в онкологической настороженности.

Ключевые слова: злокачественные и доброкачественные опухоли; онкологическая настороженность, анкетирование, предраки, малигнизация.

гласно утверждали, что им известно, что такое рак, но на деле картина оказалась намного хуже. Опухоли особый патологический процесс, который представлен новообразованной тканью, широко распространен в живой природе. Опухоли известны у всех типов живых существ в том числе и у растений. Для всех видов опухолей характерны автономный рост и размножение клеток в очаге заболевания, при этом вначале рост опухоли происходит из первоначального зачатка, без вовлечения в этот процесс окружающих здоровых клеток. Опухоль может оставаться доброкачественной или трансформироваться в злокачественную. Доброкачественная опухоль - это новообразование, клетки которого напоминают собой ткань, из которой оно происходит (эпителиальная, мышечная, соединительная ткань). Также, для этого вида опухоли, характерно частичное сохранение определённых функций ткани. Клинически такая опухоль проявляется в виде медленно растущего новообразования различных локализаций. В процессе роста опухоль постепенно отодвигает и сдавливает структуры и ткани, которые её окружают, но, при этом, никогда не прорастает в них.

Злокачественным опухолям в свою очередь принадлежит ряд специфических признаков. Признаками злокачественности в настоящее время признаются следующие.

1. Безудержный, не поддающийся контролю со стороны организма процесс роста и размножения клеток. Каждая клетка нормальной ткани обла- 
процент осведомлённых о различиях опухолей

процент опрошенных, правильно распределивших признаки

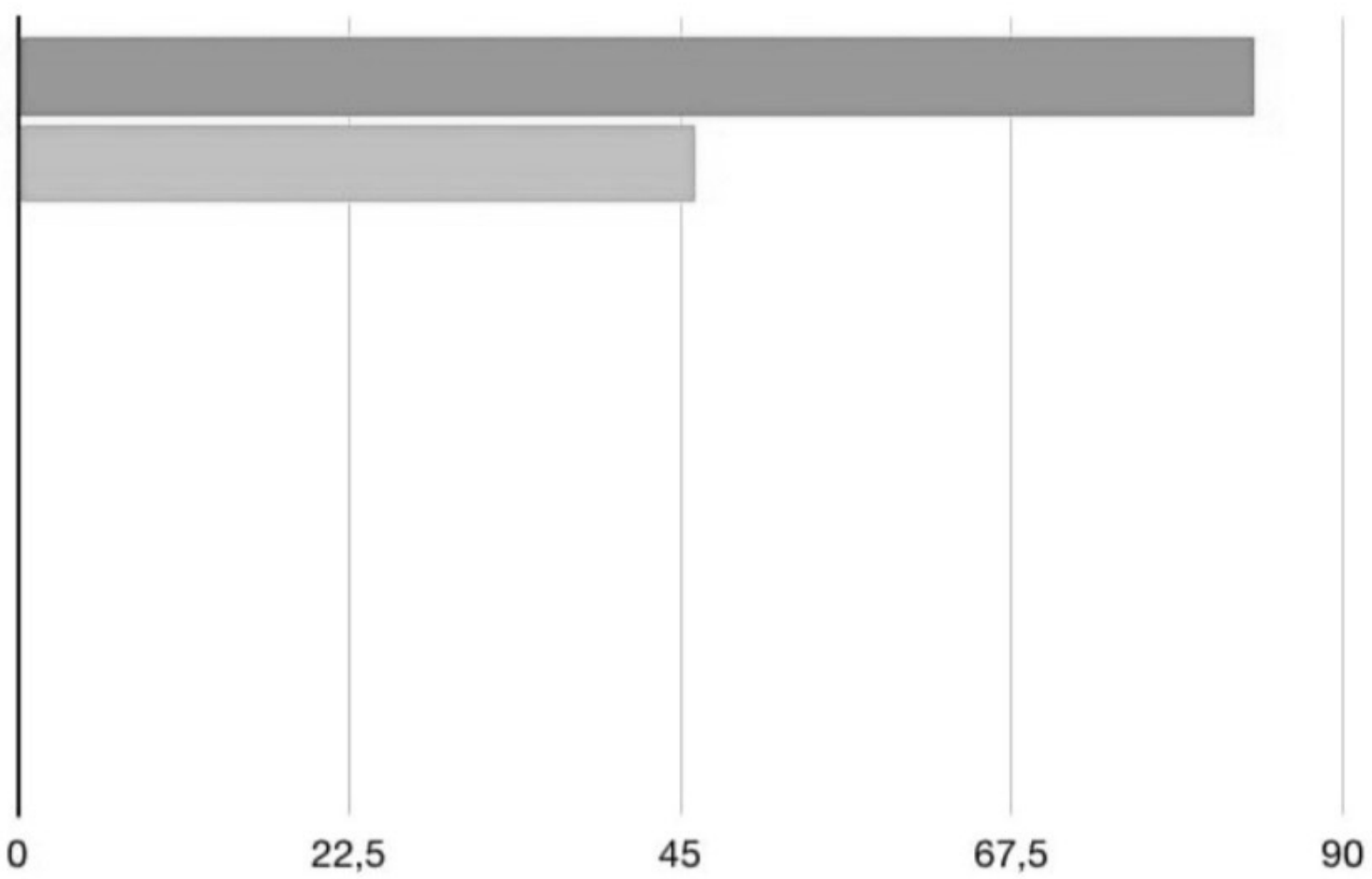

Рис. 1. Осведомленность населения о различиях доброкачественных и злокачественных опухолей

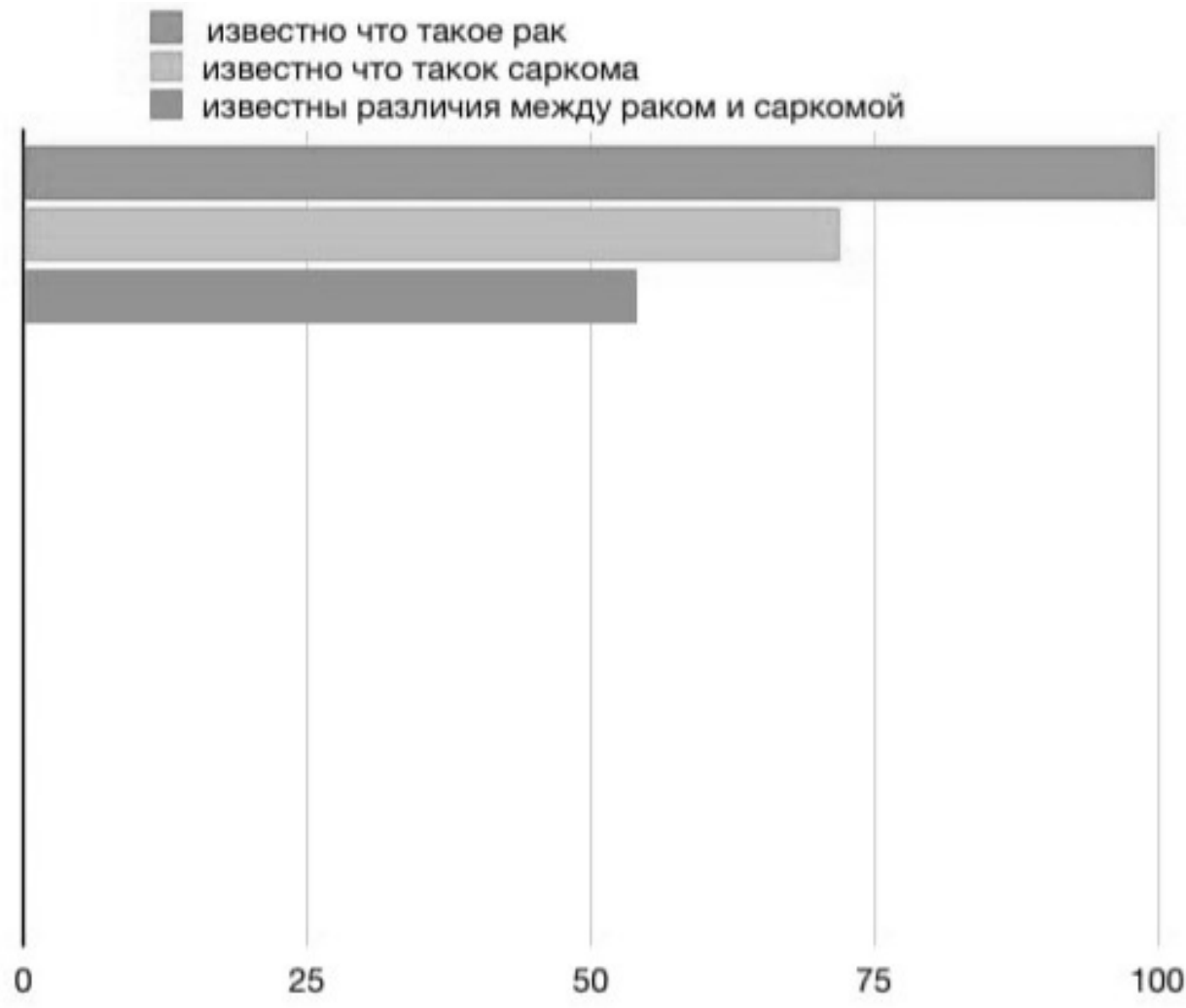

Рис. 2. Известность различий саркомы и рака 
дает способностью к апоптозу. Апоптоз - регулируемый процесс программируемой клеточной гибели. В опухолевых клетках нарушены функции саморегуляции внутри клетки, что приводит к невозможности осуществления механизмов запрограммированной гибели клеток. Без воздействия извне опухолевая клетка не погибает, или гибнет только вместе с ее носителем.

2. Метастазирование - сложный процесс образования вторичных очагов опухолевого в результате необратимых изменений, позволяющим злокачественной опухоли преодолевать физические границы первичнопораженного органа или ткани, диссеминировать и колонизировать отдаленные органы. Некоторые клетки, отделившиеся от первичной опухолевой массы, переместившиеся с током лимфы или крови в другие регионы тела, дают начало росту.

3. Инвазивный, местнодеструирующий рост. Клетки опухоли врастают в окружающие здоровые ткани, разрушая их. Главным признаком злокачественной опухоли является ее выход за пределы территории, предназначенной для данной ткани. Если опухоль прорастает в здоровую ткань, происходит инвазия внедрение опухолевых клеток - первый признак злокачественной опухоли.

В анкету был включён вопрос, касающийся вышеизложенной информации. На рисунке 1 представлены результаты опроса.

На вопрос: «Известны ли вам отличия злокачественных опухолей от доброкачественных», ответ: «Да»дали $84 \%$ опрошенных, что является положительной статистикой, но стоило углубиться в этом вопросе и картина становится строго противоположной. Был задан следующий вопрос, касающийся специфических признаков злокачественных и доброкачественные опухолей, в данном статистика указывает на обратные результаты среди 84\% опрощенных верно распределить признаки смогли менее 50\%. Для более точного анализа осведомленности населения, был задан вопрос, качающийся двух различных злокачественных Опухолей рака и саркомы. Рак - одна из разновидностей злокачественных опухолей, а именно злокачественная опухоль, исходящая из клеток эпителиальной ткани (слизистые оболочки, кожа, эпителий желез). Злокачественные опухоли, исходящие из клеток тканей, имеющих мезенхимальное происхождение (мышцы, хрящи, кости, жировая клетчатка и т.д.), называют саркомами. «Саркомы более часто развиваются у молодых людей. Рак встречается в 10-15 раз чаще, чем саркома, чаще заболевают лица пожилого возраста». [2, с. 4] На основе анкетирования и используемой выше информации по- лучены следующие статистические данные представленные на рисунке 2.

100\% опрошенных известно, что такое рак, но лишь 72\% знают, что такое саркома, назвать отличия двух представленных злокачественных опухолей смогли лишь 54\% опрошенных. Существует множество других злокачественных опухолей: меланомы, разнообразные опухоли кроветворной ткани, которые представляют не меньшую Опасность, чем рак и саркома. Злокачественные опухоли различаются по типу клеток, из которых они возникают. Виды злокачественных опухолей:

1. рак - из эпителиальных клеток (например, рак предстательной железы, лёгких, молочной железы, прямой кишки);

2. меланома - разновидность кожных злокачественных новообразований, развивающаяся из меланоцитов;

3. саркома - из соединительной ткани, костей и мышц (мезенхима);

4. лейкоз - злокачественное заболевание системы крови, для которого бластные клетки выступают в качестве субстрата опухоли;

5. лимфома - из лимфатической ткани;

6. тератома - эмбрионально-клеточная опухоль, развивающаяся из пластов эндо - экзо- и мезодермы;

7. глиома - из глиальных клеток;

8. хориокарцинома - чрезвычайно злокачественное новообразование, возникающее из элементов плодного яйца (трофобласта).

В анкете был вопрос, касающийся представленных выше разновидностей злокачественных опухолей, результаты которого изложены в рисунке 3.

Было выявлено, что о таких опухолях как тератома глиома, хориокарцинома известно менее чем $30 \%$ опрошенных.

Следующей группой в анкете были рассмотрены вопросы, касающиеся профилактики злокачественных опухолей. Профилактика в онкологии представляет собой систему мероприятий, направленных на предупреждение возникновения злокачественных опухолей и их прогрессирования. «Легче предупредить, чем лечить»- классическое изречение, которое слышал почти каждый из нас, огромный смысл вложен в эти слова, но в современных реалиях единицы следуют ему. Профилактика онкологических заболеваний делится на три этапа, по каждому из которых был задан вопрос. В понятие первичной профилактики рака входит: снижение контакта с канцерогенами, соблюдение правил личной гигиены, нормализация питания и образа жизни, повышение устойчивости организма к вредным 


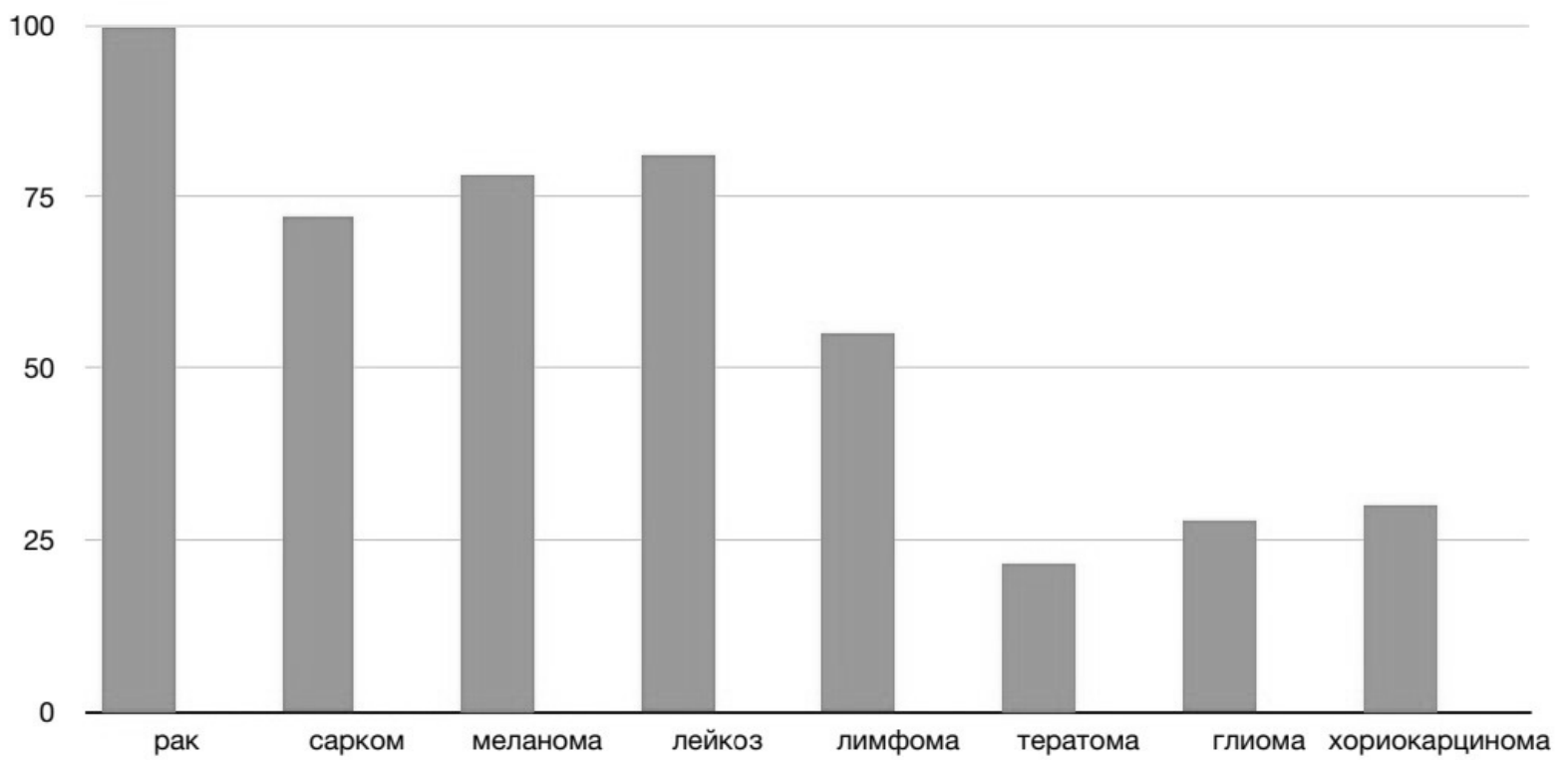

Рис. 3. Разновидности злокачественных опухолей

факторам. Использование средств индивидуальной защиты на вредных производствах. А также широкие оздоровительные мероприятия государственного масштаба в том числе: закрытие вредных производств. Планирование и строительство современных производства должны находиться под контролем, предусматривать переработку токсичных продуктов в безвредные, утилизацию отходов, строительство очистных сооружений, предохраняющих от заражения вредными продуктами окружающей среды. По результатам проведённого опроса $36,4 \%$ опрошенных, показали полную неосведомлённость в данном вопросе.

Вторичная профилактика рака представляем собой систему мер при наличии уже развившихся избыточных клеточных разрастаний с атипией эпителия и сформировавшихся предраковых состояний. Среди респондентов 56,6\% оказались не знакомы со вторичной профилактикой злокачественных новообразований.

Основным методом вторичной профилактики являются, разработанные многоцелевые скрининговые программы. Под скринингом понимают применение различных методов исследования, позволяющих диагностировать опухоль на ранней стадии, когда еще нет симптомов болезни. И несмотря на то, что целью скрининга и по существу его преимуществом является охват большого числа людей, по результатам опроса оказалось, что 52\% опрошенных процедура скрининга и его особенности оказалась совершенно не знакомы.
«Третий этап профилактики рака заключается в предупреждении прогрессирования уже возникшей злокачественной опухоли и включает в себя этапы направленным на снижение патологических влияний на организм таких как: генерализация, рецидивы. Основные способы профилактики на данном этапе это - своевременного применения рациональных методов лечения, а также квалифицированного осмотра и специального обследования лиц, получивших полный курс первичного лечения и наблюдающихся без явных признаков рецидива и метастазов, находящихся на диспансерном наблюдении» [2, с. 10]. С процессом профилактики рака на Зм этапе были осведомлены лишь $28,3 \%$ опрошенных.

Онкологическая настороженность предусматривает в рамках вторичной профилактики наблюдения за предшественниками рака - предраками. Термин «предрак» впервые был предложен в 1896 году лондонским врачом М.В. Дюбрейлем. Этот термин учёный использовал в отношении кератоза кожи как предшественника рака кожи. Лишь спустя 70 лет термин официально закрепиться Всемирной Организацией Здравоохранения в 1965 году. В своей сути предрак - это врождённые или приобретённые морфологические изменения тканей; предшественник рака. Стоит отметить, что нельзя путать предрак с фактором риска, т.к. первое уже является гистологическим субстратом, а второе только может привести к изменениям в тканях. Предраковые состояния делятся на облигатные и факультативные. Облигатные предраки - изменения 
тканей, связанные с дисрегенераторными процессами. «Чем интенсивнее пролиферация, выходящая за рамки функционально детерминированных гиперпластических процессов, сопровождающихся патологическими изменениями клеточных структур, и чем больше выражены повреждения процессов деления, тем выше вероятность развития рака». [2, с. 12] Они являются проявлениями нарушения пролиферации и созревания клеток - дисплазии.

Облигатные предраки в большинстве случаев малигнизируются. В отличие от них, факультативные предраки редко становятся злокачественными. Они являются проявлениями хронических воспалительных заболеваний, сопровождающихся дистрофическими и атрофическими изменениями тканей. В процессе развития факультативного предрака лежат регенераторные и дисрегенераторные процессы. При этом в отношении предраковых состояний применимы понятия экспозиции и эскалации временем: чем дольше существует предрак, тем выше шанс его малигнизации. Это связанно с накоплением в клетках свойств, определяющих их как злокачественные. Не стоит забывать тот факт, что не всегда опухоли находят свое проявление, но это так же не исключает их прогрессии. Об признаках или симптомах, которые относятся к раку известно 70. $8 \%$ из числа опрошенных. Больше $1 / 4$ неизвестно об них.

Необходимость полного обследования со своевременным использованием методов инструментальной диагностики остается так же на первом месте. Немалую роль играет формирование у людей более внимательного отношения к здоровью с отказом от самостоятельного лечения. Всё эти аспекты входят в понятие онкологическая настороженность. Но, к сожалению, не все понимают, что «онкологическое» как и всякое здоровье начинается прежде всего с индивидуального подхода человека.

Проявлением ответственного отношения к своему здоровью может служить посещение смотрового кабинета. Для женщин желательно посещать 1 раз в 2 года, для мужчин 1 раз в 3 года. Данные анкетирования показали, что этот минимум посещений выполняют 3/4 опрошенных. Тем не менее чуть меньше четверти (24. 5\%) совсем не посещали смотровой кабинет. Важность этого метода профилактики в том, что на осмотре появляется возможность выявить визуальные изменения органов, а также провести взятие мазков на цитологическое исследование. Возможность обнаружения гистологического изменения в анализе позволяет своевременно обнаружить клеточную атипию, клетки с выраженной гиперплазией. Важную роль в скрининге для выявления рака молочной железы играет маммография, кото- рую женщины различных возрастных групп проходят с необходимой периодичностью, а после 50 ежегодно. Участники анкеты показали, что про данный метод им известно только на $11.1 \%$.

Курение сигарет и неправильное питание является самыми распространённым вредными привычками по данным анкетирования. В табачном доме находятся мощные канцерогенные вещества - продукты сгорания смол. Сам дым в целом является раздражителем для клеток дыхательных путей и лёгких. Так же и с неправильным питанием, которое может быть нерегулярным, богатым канцерогенными пищевыми добавками и трансжирами. Стоит отметить традиции некоторых народов Востока, связанные с употреблением горячего чая, который обжигает слизистую пищевода и приводят к образованию стриктур (на это указывают данные высокой заболеваемости данным заболеванием жителей Каспийского побережья, центрально-азиатских республик, Монголии и северо-западного Китая). Раздражая слизистую оболочку дыхательных путей и ЖКТ, они активируют систему защиты всего организма. Начинаются регенераторные процессы, которые могут в целом «поломаться» - появляется дисренераторные явления: гиперплазии и дисплазии. Гиперплазия может быть без атипии, когда происходит увеличение количества клеток с дальнейшей полной дифференцировкой. Но в случае появления атипии процесс может закончиться появлением злокачественных образований. Из опрошенных 71. 4\% знают об вреде злоупотребления горячих блюд, копченностей и острых специй, как об предпосылке к развитию рака пищевода. Положительная динамика, но не стоит оставить незамеченным, что 28. 6\% ответило, что не знали об этом факте. Цель онкологической настороженности в этом ключе будет профилактика вредных привычек т.к. прекращение действия канцерогенного фактора даже на последнем этапе малигнизации приводит к обратному развитию всех процессов злокачественной прогресии.

Необходимо так же иметь особую насторожённость в отношении доброкачественных образований. Риск их малигнизации мал, но не исключается. Из таких образований стоит обратить внимание на невусы (в простонародье родинки). Это пятна, узлы, состоящие их клеток меланоцитов. Необходимо чётко следить за размером, формой и цветом любого образования на коже. По данным анкетирования отмечают изменения в размере только $20.8 \%$, форме - 16. 7\%, цвете $-14.6 \%$. Стоит отметить, что травмирование невуса крайне нежелательно, тем не менее никто не застрахован от случайного пореза во время бритья. Лишь 38. 3\% опрошенных обращают внимание и избегают невусы при бритье. Онкологическая настороженность должна ставить своей целью информирования возможного риска изменения 
данного образования после травмирования. Необходимо донести, что любое нарушение целостности приводит к делению клеток, которое может закончиться образованием нетипичных клеток - приведёт к малигнизации процесса. Нужно рекомендовать пациентам с большим риском травматизации операции по удалению невусов.

\section{Зак^ючение}

Несмотря на то, что в современном мире проблема высокой заболеваемости онкологией остается на высоком уровне, осведомлённость людей в вопросах профилактики и диагностики оказывается очень низкой. По результатам анкетирования 100\% опрошенных слышали о таком страшном заболевании как рак, но знания людей в этой области даже в век современных технологий остаются на низком уровне. Среди вышеназванных 100\% лишь 30 слышали когда-либо о таких злокачественных опухолях как: глиома, тератома. Так же не лучшим образов обстоят дела и в области профилактики. Несмотря на то, что мы повсеместно слышим о профилактике ВИЧ и СПИД, мы забываем о не менее опасных и распространённых болезнях, лишь 64\% респондентов были осведомлены о первичной Профилактике злокачественных опухолей, со вторичной профилактикой были знакомы 41,7\% опрошенных, с третьим этапом лишь 28,3\%. Не все понимают, что «онкологическое» как и всякое здоровье начинается прежде всего с индивидуального подхода человека и если некомпетентность по узкопрофильным вопросам является повсеместной, то возможно картина в области не требующих особых знаний окажется другой? Проанализировав составленную анкету, мы можем ответить на этот вопрос и картина снова оказывается неутешительной: 24,5\% совсем не посещали смотровой кабинет при норме для женщин 1 раз в 2 года, для мужчин 1 раз в 3 года. Между тем о такой важной процедуре диагностики как скрининг опрошенные осведомлены лишь на $11.1 \%$.

Положительная Статистика наблюдается в вопросе о вреде злоупотребления горячих блюд, копчёностей и острых специй, как об предпосылке к развитию рака пищевода, 71,4\% опрошенных знали об этом факте, но в других областях результаты снова оказываются неутешительными. Лишь 38, 3\% опрошенных обращают внимание и избегают невусы при бритье, отмечают изменения в размере только 20, 8\%, форме - 16, 7\%, цвете $-14,6 \%$. По итогам вышеизложенного мы приходим к выводу, что просвещённость населения остаётся на очень низком уровне. Решением данной проблемы является подготовка и внедрение программ просвещение населения в различные области деятельности.

Совершенно очевидно, что средства массовой информации играют огромную роль в просвещении и расширении возможностей людей избежать появления и прогрессирования заболевания.

\section{ЛИТЕРАТУРА}

1. Амбулаторно-поликлиническая онкология: руководство / Ш.Х. Ганцев, В.В. Старинский, И.Р. Рахматуллина, Л.Н. Кудряшова, Р.З. Султанов. Москва: ГЭОТАР-Медиа, 2012. $448 \mathrm{c}$.

2. Онкология: учебник / Вельшер Л.З., Матякин Е.Г., Дудицкая Т.К., Поляков Б.И. Москва: ГЭОТАР-Медиа, 2009. 512 с.

3. Петерсон Б.Е. Онкология. Москва: МЕДИЦИНА, 1980. 365 с

4. Петров Н.Н. Общее учение об опухолях (патология и клиника). Санкт-Петербург: Издательство журнала «Гигиена и санитария», 1910. 375 с.

5. Шабад, Л. М. 0 циркуляции канцерогенов в окружающей среде. Москва: Медицина, 1973. 368 с.

с Бисемалиева Хадиша Фархатовна ( fbisemaliev@mail.ru ), Ступин Андрей Олегович ( euaristus@mail.ru ).

Журнал «Современная наука: актуальные проблемы теории и практики» 